Original Research Article

\title{
Compare Brimonidine $0.2 \%$ versus Latanoprost $0.005 \%$ (Xalatan) in preventing intraocular pressure after YAG laser posterior capsulotomy in patients visiting ophthalmology clinic in Ardabil city
}

\author{
Habib Ojaghi, Rahim Masoumi*, Solmaz Eskandar-Sani
}

Department of Medicine, Ardabil University of Medical Science, Ardabil, Iran

Received: 12 November 2016 Accepted: 05 December 2016

*Correspondence to:

Dr. Rahim Masoumi,

Email: r.masoumi@arums.ac.ir

Copyright: (C) the author(s), publisher and licensee Medip Academy. This is an openaccess article distributed under the terms of the Creative Commons Attribution NonCommercial License, which permits unrestricted noncommercial use, distribution, and reproduction in any medium, provided the original work is properly cited.

\begin{abstract}
Background: The transient increase of intraocular pressure (IOP) following neodymium YAG laser capsulotomy can occur in a significant number of patients, which requires prophylactic treatment with IOP reducing drugs, and in some patients, postoperative IOP monitoring. This study was performed to compare the efficacy of brimonidine $0.2 \%$ versus latanoprost $0.005 \%$ (Xalatan) in preventing the IOP elevation after YAG laser posterior capsulotomy in patients visiting ophthalmology clinic in Alavi Hospital.

Methods: This study was a randomized, double-blind clinical trial that included 100 patients who had developed posterior capsule opacification (PCO) as a result of previous cataract surgery and were candidate for undergoing YAG laser posterior capsulotomy. The patients were randomly divided into two groups of 50 patients. One group received brimonidine $0.2 \%$ one hour before surgery, and the other group received Xalatan $0.005 \%$ in the night before laser surgery. In both groups the patients' IOP was measured in baseline, 1, 2, 3, 24 hours, 3 days and one week after surgery. The gathered data were analyzed using statistical methods in SPSS.16.

Results: The mean IOP, 1, 2, 3, and 24 hours, 3 days, and one week after surgery didn't show any significant difference between two groups. IOP one hour before surgery changed significantly compared to one hour after surgery and a statistically significant relationship was found between the two groups, though at other times of measurement, the differences were not significant.

Conclusions: Results showed that using Brimonidine $0.2 \%$ or Latanoprost $0.005 \%$ as prophylactic before YAG laser posterior capsulotomy could be effective in preventing IOP after treatment.
\end{abstract}

Keywords: Brimonidine, Latanoprost, Xalatan, YAG laser capsulotomy

\section{INTRODUCTION}

Cataract surgery is one of the most common ocular surgeries. The studies done in different regions have reported prevalence of the Cataract $50 \%$ and $75 \%$ in the age groups $65-74$ and at the age above 75 years respectively. ${ }^{1,2}$

The most common complication of cataract surgery is posterior capsule opacity (PCO), which results from normal posterior capsule (28 percent over five years). This capsule opacification is caused by the lens epithelial cells that have survived after the loss of the nucleus and cortex, and have proliferated. ${ }^{1-3}$ Fortunately, PCO responds to neodymium YAG laser posterior capsulotomy. Transient elevated IOP can occur in a significant number of patients following neodymium YAG laser posterior capsulotomy that requires prophylactic treatment with intraocular pressure (IOP) reducingdrugs, and in some patients, postoperative IOP monitoring. ${ }^{1,2}$

Currently, for this complication prevention, various drugs, including acetazolamide and Timololare has been used that these drugs have less side effects and need to be consumed many times by patients. Both brimonidine and Xalatan are of new drugs used for treating glaucoma, that due to their high efficacy and lower side effects are 
highly prescribed by physicians and many studies in many countries have examined the effectiveness of these drugs and have found satisfying results. And now, according to these studies, brimonidine is administered before YAG laser surgery in most countries. The aim of this study was to compare the effectiveness of Brimonidine $0.2 \%$ or Xalatan $0.005 \%$ (Latanoprost) in preventing the IOP spikes after YAG laser capsulotomy.

\section{METHODS}

This is a randomized, double-blind clinical trial study that has been done on 100 patients who were candidate for undergoing YAG laser capsulotomy in ophthalmology clinic of Alavi Hospital. The patients were randomly divided into two groups of 50 patients. One group received brimonidine $0.2 \%$ one hour before surgery, and the other group received Xalatan $0.005 \%$ in the night before laser surgery.

\section{Inclusion criteria}

Inclusion criteria were having the history of cataract surgery with posterior capsular opacification and being a candidate for undergoing YAG laser capsulotomy.

\section{Exclusion criteria}

Exclusion criteria were as follows:

1. The history of previous glaucoma,

2. The history of consumption of anti-glaucoma medications,

3. Severe adhesion of lens to surrounding tissues,

4. The history of uveitis,

5. The age under 21 years,

6. Unstable cardiovascular disease,

7. Being pregnant or lactating.

The same ophthalmologist (the researcher) examined all the patients, measured their IOP (before and after surgery), and performed YAG laser posterior capsulotomy on them.

The YAG laser capsulotomy was performed at 9 am, and then in the specified intervals (Seven times) their intraocular pressure was measured and recorded.

1. Just before surgery,

2. One hour after surgery,

3. Two hours after surgery,

4. Three hours after surgery,

5. 24 hours after surgery,

6. Three days after surgery,

7. A week after surgery.

All patients received Betamethasone eye drops every 6 hours for a week after surgery. The patients whose IOP after surgery was above $40 \mathrm{~mm} \mathrm{Hg}$ received other medicines in addition to these drugs, in order fortheir IOP to reduce. To collect data, a checklist was completed for each patient. The used drugs did not have major side effects, and the patients after signing the informed consent were included in the study. This study was approved by the ethics committee of the Ardabil Medical University. In both groups the patients' IOP was measured in baseline, 1, 2, 3, 24 hours, 3 days and one week after surgery. The gathered data were analyzed using statistical methods in SPSS.

\section{RESULTS}

The average age of patients was 67.3 years in the brimonidine group and 61.4 years in the Xalatan group. The average of used laser energy was $217 \mathrm{~mJ}$ in the brimonidine group and $268.2 \mathrm{~mJ}$ in Xalatan group. The mean IOP before surgery was $15.30 \pm 3$ in the brimonidine which was similar to Xalatan Gorup with $14.34 \pm 3.7$. The mean IOP was $13.8 \pm 4.8$ one hour after surgery in the brimonidine group, and $15.44 \pm 6.8$ in the Xalatan group, and the difference between two groups was not statistically significant (Figure 1).

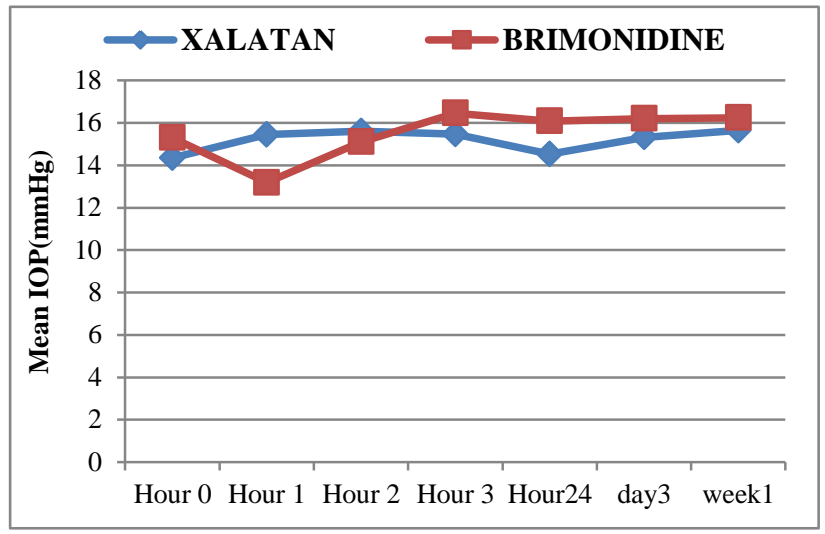

Figure 1: Mean of IOP in two groups in various times.

There was a significant change in IOP between two groups one hour after surgery, but the changes in IOP rate in other times not statistically significant between two groups (Table 1).

The type of cataract surgery in both groups in tobrimonidine and Xalatan with $70 \%$ and $60 \%$ was phacosection, respectively (Table 2).

The greatest degree of visual improvement in both groups of brimonidine and Xalatan, with $46 \%$ and $38 \%$, respectively, was "2 lines or more in Snellen chart", and there was no statistically significant difference between the two groups in terms of visual improvement after surgery (Table 3).

\section{DISCUSSION}

Studies on the use of drugs brimonidine $0.2 \%$ or latanoprost (Xalatan) $005 \%$ as anti-glaucoma eye drops for preventing IOP spikes following YAG laser 
capsulotomy showed that the impact of these drops in preventing IOP elevation was similar to other drugs. ${ }^{3-15}$

Table 1: Compare the IOP changes between two groups in various times.

\begin{tabular}{|c|c|c|c|c|c|c|c|}
\hline $\begin{array}{l}\text { Times } \\
\text { IOP changes }\end{array}$ & group & $\begin{array}{l}\text { Decrease } \\
\text { from } \\
\text { baseline }\end{array}$ & $\begin{array}{l}\text { No } \\
\text { change }\end{array}$ & $\begin{array}{l}\text { Increase } \\
\text { less than } 5 \\
\text { mmhg }\end{array}$ & $\begin{array}{l}\text { Increase } \\
\text { more than } \\
5 \text { mmhg }\end{array}$ & $\begin{array}{l}\text { Increase } \\
\text { more than } \\
10 \mathrm{mmhg}\end{array}$ & p-value \\
\hline \multirow{2}{*}{1 hour after surgery } & Brimonidine & $33(66)$ & $3(6)$ & $11(22)$ & $3(6)$ & 0 & \multirow{2}{*}{0.038} \\
\hline & Xalatan & $20(40)$ & $8(16)$ & $13(26)$ & $5(10)$ & $4(8)$ & \\
\hline \multirow{2}{*}{ 2hour after surgery } & Brimonidine & $27(54)$ & $4(8)$ & $11(22)$ & $4(8)$ & $4(8)$ & \multirow{2}{*}{0.7} \\
\hline & Xalatan & $21(42)$ & $7(14)$ & $14(28)$ & $3(6)$ & $5(10)$ & \\
\hline \multirow{2}{*}{3 hour after surgery } & Brimonidine & $25(50)$ & $1(2)$ & $11(22)$ & $7(14)$ & $6(12)$ & \multirow{2}{*}{0.3} \\
\hline & Xalatan & $25(50)$ & $4(8)$ & $13(26)$ & $2(4)$ & $6(12)$ & \\
\hline \multirow{2}{*}{24 hour after surgery } & Brimonidine & $23(46)$ & $5(10)$ & $13(26)$ & $3(6)$ & $6(12)$ & \multirow{2}{*}{0.6} \\
\hline & Xalatan & $24(48)$ & $6(12)$ & $13(26)$ & $5(10)$ & $2(4)$ & \\
\hline \multirow{2}{*}{3 days after surgery } & Brimonidine & $24(48)$ & $3(6)$ & $14(28)$ & $4(8)$ & $5(10)$ & \multirow{2}{*}{0.43} \\
\hline & Xalatan & $19(38)$ & $6(12)$ & $16(32)$ & $7(14)$ & $2(4)$ & \\
\hline \multirow{2}{*}{ one week after surgery } & Brimonidine & $19(38)$ & $3(6)$ & $22(44)$ & $6(12)$ & 0 & \multirow{2}{*}{0.66} \\
\hline & Xalatan & $16(32)$ & $6(12)$ & $20(40)$ & $7(14)$ & $1(2)$ & \\
\hline
\end{tabular}

Table 2: Type of cataract surgery in two groups.

\begin{tabular}{|lllllllll|l|}
\hline $\begin{array}{l}\text { Type of surgery } \\
\text { groups }\end{array}$ & \multicolumn{2}{l}{ Phacoemulsification } & \multicolumn{2}{l}{ Phacosection } & \multicolumn{2}{l|}{ Extra-capsular cataract extraction } & Total \\
\hline Brimonidine & $\mathbf{N}$ & $\mathbf{\%}$ & $\mathbf{N}$ & $\mathbf{\%}$ & $\mathbf{N}$ & $\mathbf{\%}$ & $\mathbf{N}$ & $\mathbf{\%}$ \\
\hline Xalatan & 10 & 20 & 35 & 70 & 5 & 10 & 50 & 100 \\
\hline
\end{tabular}

Table 3: The degree of improvement in vision after YAG in two groups.

\begin{tabular}{|c|c|c|c|c|c|c|c|c|c|c|c|c|c|}
\hline \multirow{2}{*}{$\begin{array}{l}\text { Degree } \\
\text { improvement } \\
\text { groups }\end{array}$} & \multicolumn{2}{|c|}{$\begin{array}{l}\text { No } \\
\text { change }\end{array}$} & \multicolumn{2}{|c|}{$\begin{array}{l}\text { From } \\
\text { H.M to } \\
\text { F.C }\end{array}$} & \multicolumn{2}{|c|}{$\begin{array}{l}\text { From F.C } \\
\text { to CLEAR } \\
\text { F.C }\end{array}$} & \multicolumn{2}{|c|}{$\begin{array}{l}\text { From F.C } \\
\text { to Snellen } \\
\text { chart }\end{array}$} & \multicolumn{2}{|c|}{$\begin{array}{l}\text { One degree } \\
\text { improvement in } \\
\text { Snellen chart }\end{array}$} & \multicolumn{2}{|c|}{$\begin{array}{l}\text { two degree or more } \\
\text { improvement in } \\
\text { Snellen chart }\end{array}$} & \multirow[t]{2}{*}{$\begin{array}{l}\text { p- } \\
\text { value }\end{array}$} \\
\hline & $\mathbf{N}$ & $\%$ & $\mathbf{N}$ & $\%$ & $\mathbf{N}$ & $\%$ & $\mathbf{N}$ & $\%$ & $\mathbf{N}$ & $\%$ & $\mathbf{N}$ & $\%$ & \\
\hline Brimonidine & 8 & 16 & 0 & 0 & 5 & 10 & 9 & 18 & 5 & 10 & 23 & 46 & \multirow{2}{*}{0.44} \\
\hline Xalatan & 6 & 12 & 4 & 8 & 5 & 10 & 10 & 20 & 6 & 12 & 19 & 38 & \\
\hline
\end{tabular}

Teresa, Nancy and Unal in their study, showed that the use of brimonidine $0.15 \%$ before surgery is comparable to the efficacy and safeness of apraclonidine $0.5 \%$ and $0.1 \%$ in preventing IOP elevation after laser anterior segment capsulotomy. $5,6,16$

Seong et al in a study identified the positive influence of brimonidine $0.2 \%$ as an eye drop in preventing IOP elevation after YAG laser capsulotomy. ${ }^{7}$

Yeom and et al in a study used two different concentrations of brimonidine $(0.2 \%$ and $0.15 \%)$ and showed their high effectiveness in preventing IOP rise after YAG laser capsulotomy and also they suggest that both drugs had a similar impact on preventing IOP increase. ${ }^{4}$

Negar and et al in a study showed that in patients with high IOP and wide-angle glaucoma, latanoprost is more effective in IOP control than laser trabeculoplasty. ${ }^{11}$
Robert and et al in a study showed that the effect of latanoprost alone is equal to the combined effect of Dorzolamide / Timolol in lowering IOP. ${ }^{3}$

Catherine and et al in a study demonstrated that Latanoprost decreases the IOP elevation in patients after YAG laser iridotomy (LI). ${ }^{12}$ In the present study, like other studies, both medications were proved to be effective in controlling IOP after surgery.

Considering the results obtained from two groups, no significant difference was seen between groups regarding the mean pressurein the intervals of measurement. But in terms of peak rise in IOP, the greatest increase in the brominidine group (16 patients) was observed 24 hours after surgery, and in the Xalatan group (12 patients) three days after surgery. However, this difference was no statistically significant. The groups varied from each other significantly concerning IOP change one hour after 
surgery, while it was not significant in other measurements carried out at other times.

As the patients in this study underwent YAG laser capsulotomy when the administered drugs were in their peak effect, that is, Bromindine $0.2 \%$ one hour before surgery (with a peak effect 2 hours after dosing), and Xalatan $0.005 \%$ the night before surgery at 10 p.m. (with a peak effect 10-14 hours after dosing), and since the previously done studies haven't taken Xalatan as such, they obtained results and statistics in this study may yield more accurate outcomes.

Moreover, in as much as the risk of IOP elevation after surgery is until 3 days after the surgery, in this study, IOP was measured 1 hour, 2 hours, 3 hours, 24 hours, 3 days, and one week after surgery. By so doing, it can be claimed that the present study can be more accurate in IOP monitoring after surgery than other studies undertaken in this area to date.

Haydar et al, examined the effect of Latanoprost $0.005 \%$ and $0.2 \%$ brimonidine in preventing IOP elevation after phacoemulsification and intraocular lens implantation surgery, and found the efficacy of two eye drops was similar. ${ }^{8}$

Novak-Laus et al, in their study found that latanoprost or brominidine are more effective than pilocarpine in reducing IOP following YAG laser iridotomy. ${ }^{9}$

William et al. also compared the effect of brimonidine $0.2 \%$ and Unoprostone $0.15 \%$ (Another prostaglandin analog) on IOP reduction and found that consuming brimonidine twice a day has greater effect on reducing peak IOP than Unoprostone. ${ }^{14}$

\section{CONCLUSION}

Based on the results of this study, it can be said that the prophylactic use of a single dose of latanoprost $0.005 \%$ before YAG posterior laser capsulotomy is similar to use of brimonidine $0.2 \%$, and is effective in preventing IOP rise. Because elevated IOP after YAG posterior laser capsulotomy occurs in most patients, and requires drug treatment after surgery, it is suggested that a single dose of brimonidine or latanoprost before YAG laser capsulotomy be used as a prophylactic medicine, so that there wouldn't be need for consuming multiple drugs after surgery.

Funding: No funding sources Conflict of interest: None declared

Ethical approval: The study was approved by the Institutional Ethics Committee

\section{REFERENCES}

1. Rapuano CJ, Belin MW, Boxer Wachler BS, Donnenfeld ED, Feder RS, Rosenfeld SI, et al.
Collagen shrinkage procedures. Refractive Surgery. Section 13. Singapore: American Academy of Ophthalmology (AAO); 2008:150-163.

2. Riordan-Eva P, FRCS, FRCO phth, Whitcher JP, Albiani DA. Vaughan and Asbury's General Ophthalmology $17^{\text {th }}$ Edition; 2007:178-179.

3. Fechtner RD, Airaksinen PJ. Efficacy and tolerability of thedorzolamide $2 \%$ timolol $0.5 \%$ combination (COSOPTTM) versus latanoprost $0.005 \%$ (XALATANTM) in the treatment of ocular hypertension or glaucoma: results from two randomized clinical trials. Acta Ophthalmologica Scand inavica. 2004;82:42-8.

4. Yeom HY, Lee JH, Hong YJ, Seong GJ. Brimonidine $0.2 \%$ Versus Brimonidine Purite $0.15 \%$ : Prophylactic Effect on IOP Elevation After Nd: YAG Laser Posterior Capsulotomy. Journal of Ocular Pharmacology and Therapeutics. 2006;22(3):176-81.

5. Chen TC. Brimonidine $0.15 \%$ versus apraclonidine $0.5 \%$ for prevention of intraocular pressure elevation after anterior segment laser surgery. Journal of Cataract and Refractive Surgery. 2005;31:1707-12.

6. Yuen NSY, Cheung P, Hui SP. Comparing Brimonidine $0.2 \%$ to Apraclonidine $1.0 \%$ in the privention of intraocular pressure elevation and their pupillary effects following Laser peripheral Iridotomy. Japanese Ophthalmological Society. 2005;49:89-92.

7. Seong GJ, Lee JH, Lim SJ. Effect of $0.2 \%$ Brimonidine in preventing intraocular pressure elevation after Nd: YAG laser posterior capsulotomy. Ophthalmic Surg Laser. 2000;31(4):308-14.

8. Erdogan H, Toker MI, Arici MK, Topalkara A. Effect of latanoprost $0.005 \%$ and Brimonidine $0.2 \%$ on intraocular pressure after Phacoemulsification and intraocular Lens implantation surgery. Japanese Ophthalmological Society. 2004;48:598-601.

9. Novak-Laus K, Masnec-Paskvalin S. Use of antiglaucoma therapy to reduce acute intraocular pressure rise following neodymium: YAG laser iridotomy in angle-closure glaucoma patients. Acta Med Croatica. 2006;60(2):113-6.

10. Minello, Antonieta, Pereira A. Efficacy of topic ocular hipotensive agents after posterior capsulotomy. Arquivos Brasileiros de Oftalmologia 2008;71(5):706-10.

11. Nagar M, Ogunyomade A. A randomised prospective study comparing selective laser trabeculoplasty with latanoprost for the control of intraocular pressure in ocular hypertension and open angle glaucoma. $\mathrm{Br} \mathbf{J}$ Ophthalmol. 2005;89(11):1413-7.

12. Liu CJ, Ching-Yu C, Shu-Chiung C, Chiu AW, Chou JCK, Wen-Ming $\mathrm{H}$, et al. Use of latanoprost to reduce acute intraocular pressure rise following neodymium: Yag laser iridotomy. Acta Ophthalmologica Scandinavia; 2002;282-286.

13. Gartaganis SP, Mela EK, Katsimpris JM. Use of topical brimonidine to prevent intraocular pressure elevations following $\mathrm{Nd}$ : YAG-laser posterior 
capsulotomy. Ophthalmic Surg Lasers. 1999;30(8):647-52.

14. Stewart WC, Stewart JA. The Safety and efficacy of unoprostone $0.15 \%$ versus brimonidine $0.2 \%$. Acta Ophthalmologica Scand inavica. 2004;82:161-5.

15. Chevrier RL, Assalian A, Duperre J. Apraclonidine $0.5 \%$ versus brimonidine $0.2 \%$ for the control of intraocular pressure elevation following anterior segment laser procedures. Ophthalmic Surg Lasers. 1999,Mar:30(3):199-204.

16. Unal M, Yucel I, Akar Y. Brinzolamid 1\% versus apraclonidine $0.5 \%$ to prevent intraocular pressure elevation after neodymium: YAG laser posterior capsulotomy. Journal of Cataract and Refractive Surgery. 2006;32:1499-502.

Cite this article as: Ojaghi $\mathrm{H}$, Masoumi $\mathrm{R}$, Eskandar-Sani S. Compare Brimonidine $0.2 \%$ versus Latanoprost $0.005 \%$ (Xalatan) in preventing intraocular pressure after YAG laser posterior capsulotomy in patients visiting ophthalmology clinic in Ardabil city. Int J Basic Clin Pharmacol 2017;6:189-93. 